\title{
Crevice Corrosion Performance of 436 Ferritic Stainless Steel Studied by Different Electrochemical Techniques in Sodium Chloride Solutions with Sulfate Addition
}

\author{
Jia-Ming Wang ${ }^{1} \cdot$ Sheng-Sheng Qian ${ }^{1} \cdot$ Yuan-Yuan Liu ${ }^{1} \cdot$ Yang-Ting Sun ${ }^{1} \cdot$ Yi-Ming Jiang $^{1} \cdot$ Jin Li $^{1}$ \\ Received: 14 November 2017/Revised: 6 January 2018/Published online: 9 April 2018 \\ (c) The Chinese Society for Metals and Springer-Verlag GmbH Germany, part of Springer Nature 2018
}

\begin{abstract}
The crevice corrosion behaviors of 436 stainless steels in chloride-containing solutions with sulfate addition were studied using potentiodynamic, galvanostatic and repassivation potential measurements. The results of these electrochemical tests were compared and discussed. Galvanostatic test was proved to be the most powerful technique in detecting the crevice corrosion of 436 stainless steels, while the repassivation potential measurement was the most time-saving method in this study. Sulfate ions have inhibited the crevice corrosion of 436 stainless steels in chloride-containing solution, which may result from the effects of competitive adsorption and the IR drop mechanism.
\end{abstract}

Keywords Crevice corrosion · Ferritic stainless steels · Electrochemical techniques · Sulfate ions · Competitive adsorption . IR drop mechanism

\section{Introduction}

436 stainless steel is a new upgraded product of modern middle-chromium ferritic stainless steel, which is widely used as an alternative to traditional 430 and 304 stainless steels for many applications, such as vehicle exhaust systems, household electrical appliances and water heaters, due to its superior performance and economical price. However, localized corrosion especially crevice corrosion has always been considered as a threatening factor to the use of ferritic stainless steels in seawater containing chloride and sulfate anions.

Crevice corrosion is a typical localized corrosion that is similar to pitting corrosion. The process and mechanism of the crevice corrosion have been widely investigated by many researchers. Oldfield and Sutton discussed the formation of acidity within the crevice, which finally lead to the rapid dissolution of alloys inside crevice [1, 2]. Pickering and Frankenthal theorized that the initiation of

Available online at http://link.springer.com/journal/40195.

Jin $\mathrm{Li}$

corrosion@fudan.edu.cn

1 Department of Materials Science, Fudan University, Shanghai 200433, China crevice corrosion requires IR drop within the crevice solution, which shifts the metal potential inside the crevice from passive region to active region [3].

Several electrochemical techniques have been used to study crevice corrosion. The potentiodynamic polarization test [4-8] is the most widely used technique examining crevice corrosion. On this basis, Tsujikawa-Hisamatsu Electrochemical (THE) technique $[9,10]$ and the potentiodynamic-galvanostatic-potentiodynamic (PD-GS-PD) technique [11-15] have been developed to study crevice corrosion.

Buffer solutions would be required during the as-mentioned electrochemical tests in chloride-containing solutions to prohibit stainless steels from being aggressively attacked in a very quick process, which guarantee to distinguish crevice corrosion from any other localized corrosion. The inhibition effects of different anions such as nitrate ions and sulfate ions present in seawater during corrosion procedures have been studied by many researchers. Sulfate ions are usually considered as the corrosion inhibitor for alloys in chloride-containing solutions. Zuo et al. [16, 17] studied the positive effects of some anions on metastable pitting potentials of $316 \mathrm{~L}$ stainless steels. Sulfate ions are regarded as the inhibitor to suppress the local corrosion. Chou et al. $[18,19]$ found that the addition of sulfate ions to chloride solutions has a 
positive effect on both the $E_{\mathrm{pit}}$ and CPT of high-entropy alloy $\mathrm{Co}_{1.5} \mathrm{CrFeNi}_{1.5} \mathrm{Ti}_{0.5} \mathrm{Mo}_{0.1}$ when the concentration ratio of the sulfate ions and chloride ions is higher than 0.5 . Niu et al. [20, 21] investigated the inhibition effects of sulfate ions with different concentrations toward $13 \mathrm{Cr}$ steels in chloride-containing solutions.

In this work, the crevice corrosion behaviors of 436 stainless steels in sodium chloride solutions were investigated by anodic polarization tests, galvanostatic tests and repassive potential tests, and the optimum method among these techniques was discussed. The inhibition effects and mechanism of sulfate anions were also discussed.

\section{Experimental}

\subsection{Specimen Preparation}

The material studied in this research was 436 ferritic stainless steel with the composition listed in Table 1. The specimens were cut into small pieces with a dimension of $20 \mathrm{~mm} \times 30 \mathrm{~mm} \times 1.5 \mathrm{~mm}$ and a $9-\mathrm{mm}$-diameter hole in the middle for electrochemical tests. The samples were ground mechanically with abrasive papers up to 1000 grit, rinsed in alcohol and deionized water successively, and dried at $50{ }^{\circ} \mathrm{C}$ in the temperature humidity chamber for over $24 \mathrm{~h}$ before electrochemical tests.

The crevice formers were made of PTFE materials according to ASTM-G48 [22]. Two washers with 12 teeth were fastened to the specimen by a bolt and a nut, leaving a crevice of about $50 \mu \mathrm{m}$ in width. The crevice former and specimen used in the tests are shown in Fig. 1. Crevice corrosion preferentially occurred under such crevice formers, which guaranteed the results of this work, were mostly related to crevice corrosion.

\subsection{Electrochemical Tests}

The potentiodynamic polarization tests, galvanostatic tests and repassivation potential measurements were used to evaluate the crevice corrosion of UNS S43600 in this study. The electrochemical experiments were conducted in 0.01-1 M sodium chloride solutions at $30{ }^{\circ} \mathrm{C}$. And sodium sulfate solutions were added as buffer solution in some

Table 1 Chemical composition (wt\%) of the tested 436 ferritic stainless steel

\begin{tabular}{lllllllll}
\hline $\mathrm{C}$ & $\mathrm{Mn}$ & $\mathrm{Si}$ & $\mathrm{Cr}$ & $\mathrm{P}$ & $\mathrm{S}$ & $\mathrm{Mo}$ & $\mathrm{Nb}$ & $\mathrm{Fe}$ \\
\hline 0.01 & 0.28 & 0.51 & 17.66 & 0.023 & 0.001 & 0.87 & $<0.01$ & $\mathrm{Bal}$. \\
\hline
\end{tabular}

circumstances when chloride ions were too aggressive to ferritic stainless steels.

All tests were carried out in a three-electrode system using an electrochemical workstation of CHI660e (Chenhua instrument corporation, China). A platinum foil and a saturated calomel electrode (SCE) were used as counter and reference electrodes, respectively, while the specimen equipped with the crevice former worked as the working electrode. All the potentials mentioned in this paper were referred to SCE.

Prior to each electrochemical test, the 436 specimens with crevice formers were cathodically polarized at -0.9 $\mathrm{V}_{\mathrm{SCE}}$ for $240 \mathrm{~s}$ to remove the spontaneous oxide layers. Then, the open-circuit potential (OCP) was monitored for $3600 \mathrm{~s}$ to reach a stable state defined as $E_{\mathrm{OCP}}$.

\subsubsection{Potentiodynamic Polarization Tests}

The potentiodynamic scans were run from the cathodic to the anodic potential, which started near $V_{\text {ocp }}$ at a scan rate of $10 \mathrm{mV} / \mathrm{min}$ in $0.01-1 \mathrm{M}$ sodium chloride solutions at $30{ }^{\circ} \mathrm{C}$. The potential was recognized as the crevice breakdown potential $\left(E_{\mathrm{b}}\right)$ when the current density reached $100 \mu \mathrm{A} / \mathrm{cm}^{2}$. The natural corrosion potential was defined as $E_{\text {corr }}$.

\subsubsection{Galvanostatic Tests}

A constant current at the density of $100 \mu \mathrm{A} / \mathrm{cm}^{2}$ was applied on the UNS S43600 samples, and the $E-t$ curve was monitored for $7200 \mathrm{~s}$. Then, the current was applied on different samples for various time ranged from 2500 to $5500 \mathrm{~s}$ to corrode the samples to different degrees.

\subsubsection{Repassivation Potential Measurements}

Figure 2 is the process diagram of repassivation potential measurements, which shows the simplified steps of this technique.

The $I-t$ curve was recorded with an applied potential of $0.8 \mathrm{~V}_{\mathrm{SCE}}$ to monitor the current density. If the current density immediately reached $500 \mu \mathrm{A} / \mathrm{cm}^{2}$ or increased continuously for more than $20 \mathrm{~s}$, it indicated the occurrence of crevice corrosion and the applied potential should be reduced to $E_{\mathrm{OCP}}$ to passivate the sample. If the current density remained less than $4 \mu \mathrm{A} / \mathrm{cm}^{2}$ or decreased as time went by, the test should be extended for another $15 \mathrm{~min}$. The applied potential should also be reduced to $E_{\mathrm{OCP}}$ if corrosion occurred in the extended period.

After reducing the applied potential to $E_{\mathrm{OCP}}$, the $I-$ $t$ curve was recorded for $15 \mathrm{~min}$ to determine whether the specimen could be repassivated. If the current density reduced as time went by or remained below $2 \mu \mathrm{A} / \mathrm{cm}^{2}$, it 

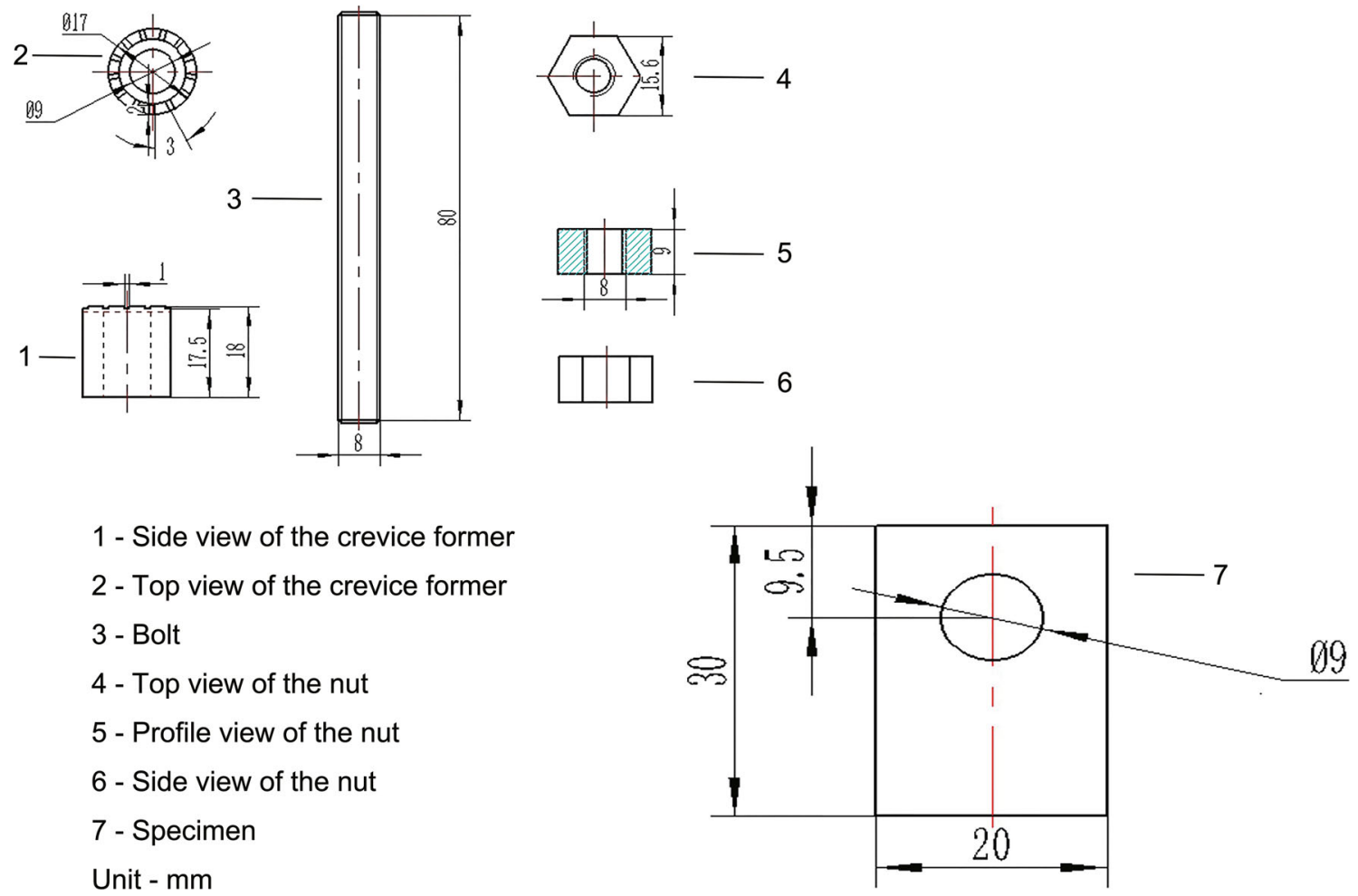

Fig. 1 Crevice former and specimens used in the test (dimensions in millimeters)

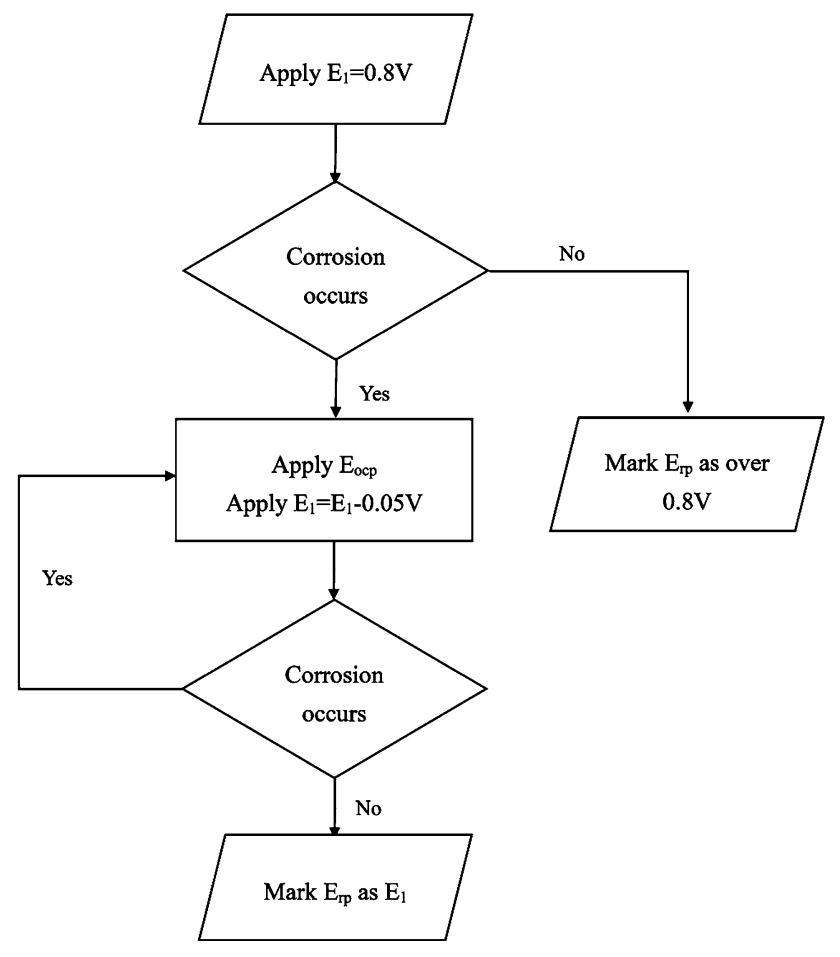

Fig. 2 Process diagram of repassivation potential measurements

would be recognized that the specimen could be repassivated at such potential. And the applied potential should be moved to $0.8 \mathrm{~V}_{\mathrm{SCE}}$ to induce crevice corrosion again and then reduced to $50 \mathrm{mV}$ above the present applied potential. If the current density increased as time went by or fluctuate in a wide range, it would be recognized that the specimen could not be repassivated under such potential.

Such operations were repeated until the applied potential under which the specimen could not be repassivated was determined. The highest applied potential to repassivate the specimen was defined as the repassivation potential $\left(E_{\mathrm{rp}}\right)$ of the 436 sample. If no sign of crevice corrosion occurrence could present at $0.8 \mathrm{~V}_{\mathrm{SCE}}$ after $15 \mathrm{~min}$, the test should be ended and the $E_{\mathrm{rp}}$ was marked as over $0.8 \mathrm{~V}_{\mathrm{SCE}}$.

\subsection{Characterizations}

The corrosion morphologies of the specimens underwent tests of different time were observed to evaluate the severity of corrosion using 4XCE optical microscope and JSM-6701F scanning electron microscope (SEM).

\section{Results and Discussion}

\subsection{Potentiodynamic Polarization Tests}

The potentiodynamic scans were conducted for 436 specimens in $0.01,0.1$ and $1 \mathrm{M}$ sodium chloride solutions at $30{ }^{\circ} \mathrm{C}$. As shown in Fig. 3, the current density increased 


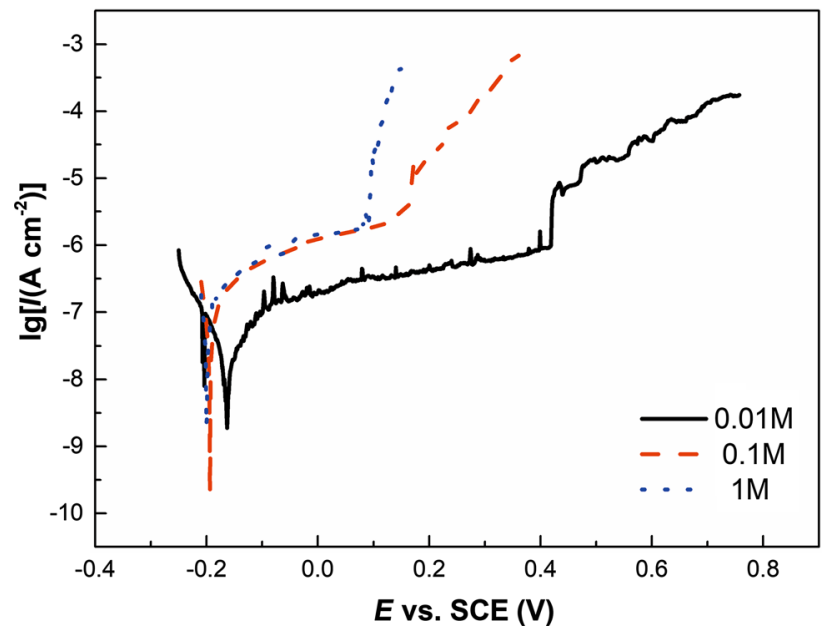

Fig. 3 Polarization curves of creviced 436 stainless steel specimens at $30{ }^{\circ} \mathrm{C}$ in $0.01,0.1$ and $1 \mathrm{M}$ sodium chloride solutions

and the breakdown potential decreased with the increase in sodium chloride solution concentration. In $0.01 \mathrm{M}$ sodium chloride solution, a broad passive region was observed with a passive current density of $0.1 \mu \mathrm{A}$. In $0.1 \mathrm{M}$ sodium chloride solution, the breakdown potential decreased to $0.3 \mathrm{~V}_{\mathrm{SCE}}$ and the passive current density increased to $1 \mu \mathrm{A} /$ $\mathrm{cm}^{2}$. The natural corrosion potentials in both experiments were around $-0.2 \mathrm{~V}_{\mathrm{SCE}}$. In $1 \mathrm{M}$ sodium chloride solution, the breakdown potential decreased further to $0.1 \mathrm{~V}_{\mathrm{SCE}}$ and the passive current density maintained at $1 \mu \mathrm{A} / \mathrm{cm}^{2}$. Chloride ions were proved of obvious influence on the corrosion behaviors. This conclusion is widely supported by many studies, in which chloride ions are regarded as corrosive ions for stainless steels [23-28].

Figure 4a-e shows the optical images of 436 specimens after potentiodynamic polarization tests stopped at various current densities in the solutions containing different chloride ions concentrations. No crevice corrosion was presented for the specimens after polarization scan stopped at $100 \mu \mathrm{A} / \mathrm{cm}^{2}$, due to the reason as some studies stated that an incubation period is essential for crevice corrosion to grow up $[2,29]$. Severe corrosion attacks including pitting corrosion and crevice corrosion occurred on the surface of samples in the experiment that the polarization scanning stopped at $1 \mathrm{~mA} / \mathrm{cm}^{2}$. However, it is hard to distinguish the types of local corrosions in these potentiodynamic scans. The crevice corrosion performance of 436 stainless steel samples cannot be identified by the potentiodynamic tests under current conditions.

\subsection{Galvanostatic Tests}

Galvanostatic tests were designed to solve the problems that occurred in polarization tests. This technique mainly aimed to weaken the aggressiveness of solutions only containing chloride ions and provided sufficient time for crevice corrosion to be induced. To reach these two goals, sulfate ions were added into sodium chloride solutions and the incubated period for crevice corrosion was extended.

Figure 5 shows the $E-t$ curve obtained from the galvanostatic test conducted in $1 \mathrm{M}$ sodium chloride $+0.2 \mathrm{M}$ sodium sulfate solutions for $7200 \mathrm{~s}$. The potential sharply decreased at the beginning of the test, and then the decreasing speed of potential slowed down as test proceeding. The potential finally reached to a stable state around $-0.1 \mathrm{~V}_{\mathrm{SCE}}$.

Figure 6a-d shows the optical images of 436 specimens underwent galvanostatic tests of $2500 \mathrm{~s}, 4000 \mathrm{~s}$ and $5500 \mathrm{~s}$, respectively. Potentiodynamic polarization test was conducted in $1 \mathrm{M}$ sodium chloride solution, which was more aggressive than the solution used in galvanostatic tests. The specimen surface shows few corrosion attacks after a galvanostatic test of $2500 \mathrm{~s}$ as presented in Fig. 6a. Nearly, no crevice corrosion attacks can be observed around the area under the crevice former. Obvious crevice corrosion attacks appeared on the specimen in Fig. $6 \mathrm{~b}$ and the most severe crevice corrosion attacks could be observed on the specimen surface in Fig. 6c, which was tested for $5500 \mathrm{~s}$. There are also crevice corrosion attacks observed on the specimen surface showed in Fig. 6d, which underwent the polarization test in a more aggressive solution. However, these corrosion attacks are not as severe as those observed in Fig. $6 \mathrm{~b}$ and c.

Therefore, the galvanostatic tests are more powerful than potentiodynamic polarization tests considering the effects of crevice corrosion attacks. In galvanostatic tests, the severity of crevice corrosion raised as increasing the test time from $2500 \mathrm{~s}$ to $5500 \mathrm{~s}$, which can provide enough incubation time for the growth of crevice corrosion. The morphology also proved that the crevice corrosion did occur when the potential of the specimen surface was still in the passive region as shown in the polarization results. It can be explained by the IR drop mechanism [3], which stated that IR drop exists between the specimen surface inside the crevice and the surface outside the mouth of the crevice. The potential of the specimen surface beneath the crevice former is over its breakdown potential while that of the outer surface is in its passive region. The activation converts to passivation from the surface inside the crevice and outside the crevice. The dissolution of 436 within the crevice was accelerated because of the drop of local potential, which finally led to the corrosion.

\subsection{Repassivation Potential Measurements}

Potentiodynamic polarization and galvanostatic tests were proved of effects of crevice corrosion of 436 stainless steels. However, problems also existed in these two 


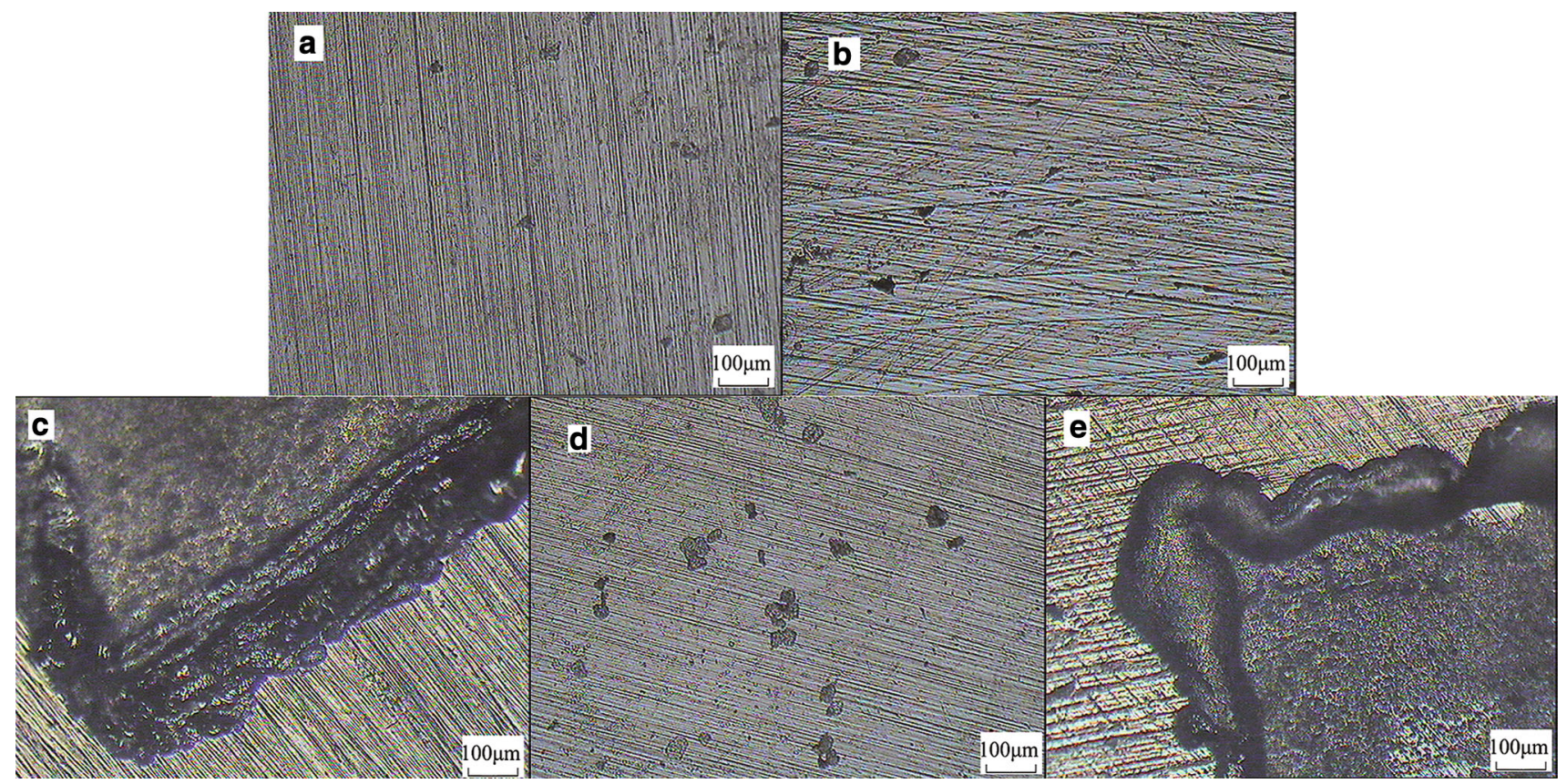

Fig. 4 Optical images of 436 specimens after potentiodynamic polarization tests stopped at a $0.1 \mathrm{~mA}$ in $0.01 \mathrm{M}$ sodium chloride b $0.1 \mathrm{~mA}$ in $0.1 \mathrm{M}$ sodium chloride $\mathbf{c} 1 \mathrm{~mA}$ in $0.1 \mathrm{M}$ sodium chloride $\mathbf{d} 0.1 \mathrm{~mA}$ in $1 \mathrm{M}$ sodium chloride e $1 \mathrm{~mA}$ in $1 \mathrm{M}$ sodium chloride

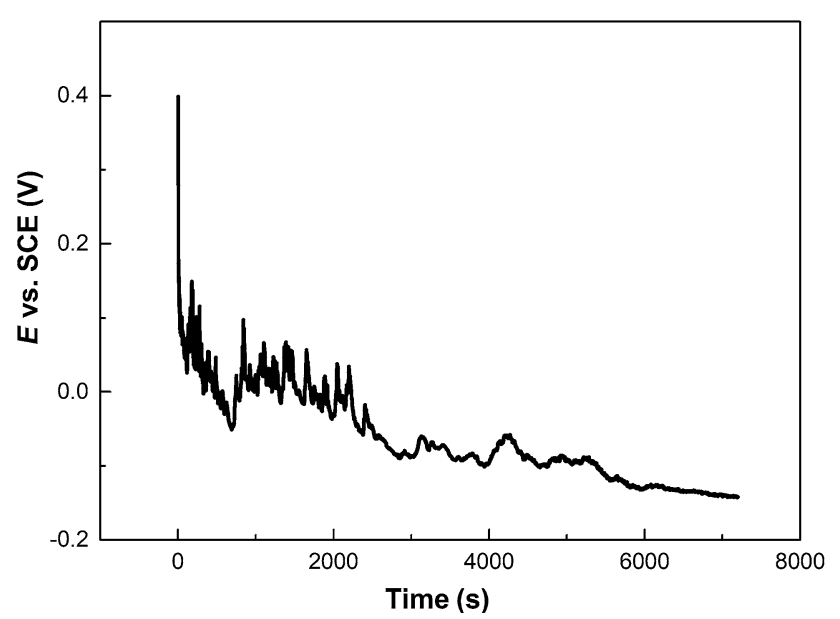

Fig. $5 E-t$ curve of the creviced 436 specimens in $1 \mathrm{M}$ sodium chloride and $0.2 \mathrm{M}$ sodium sulfate solutions for $7200 \mathrm{~s}$ galvanostatic test at $30{ }^{\circ} \mathrm{C}$

electrochemical techniques. For example, the time needed for the tests is always considered too long. Repassivation potential measurements met the demand to shorten the process of evaluating the corrosion behaviors of the alloys.

Figure 7 shows the repassivation potentials measured and the breakdown potentials obtained from polarization tests. These tests were conducted in the sodium chloride solution with concentrations of $0.01,0.1$ and $1 \mathrm{M}$, respectively.

It is revealed that the repassivation potentials followed the same law as the breakdown potentials. The same trend was observed among these statistics. Both potentials remained nearly the same in 0.01 and $0.1 \mathrm{M}$ sodium chloride solutions and decreased sharply in $1 \mathrm{M}$ sodium chloride solution. It could be explained by the similar principle of such two potentials, both of which would be, to some extent, recognized as the critical corrosion potential.

According to this result, it was convinced that the technique of repassivation potential measurements was qualified as an alternative technique for evaluating characters of crevice corrosion for 436 ferritic stainless steels.

\subsection{Effects of Sulfate lons Added into Chloride- Containing Solutions}

It is mentioned in Sects. 3.1 and 3.2 that chloride ions were too aggressive for 436 stainless steels, since the crevice corrosion was hard to be identified and observed easily without any other kinds of corrosion. Thus, sulfate ions were introduced into test solutions working as a kind of corrosion inhibitors. The decision to use sulfate ions was not only because they had the effects of suppressing corrosion behaviors, but also their widely existence in the natural world such as seawater. They can be easily collected and used at low prices.

Figure $8 \mathrm{a}$ and $\mathrm{b}$ shows the polarization curves of 436 stainless steels after tests in $0.1 \mathrm{M}$ sodium chloride solutions and $1 \mathrm{M}$ sodium chloride solutions with sulfate ions added at the concentration of none, 0.1 and $0.2 \mathrm{M}$, respectively. 

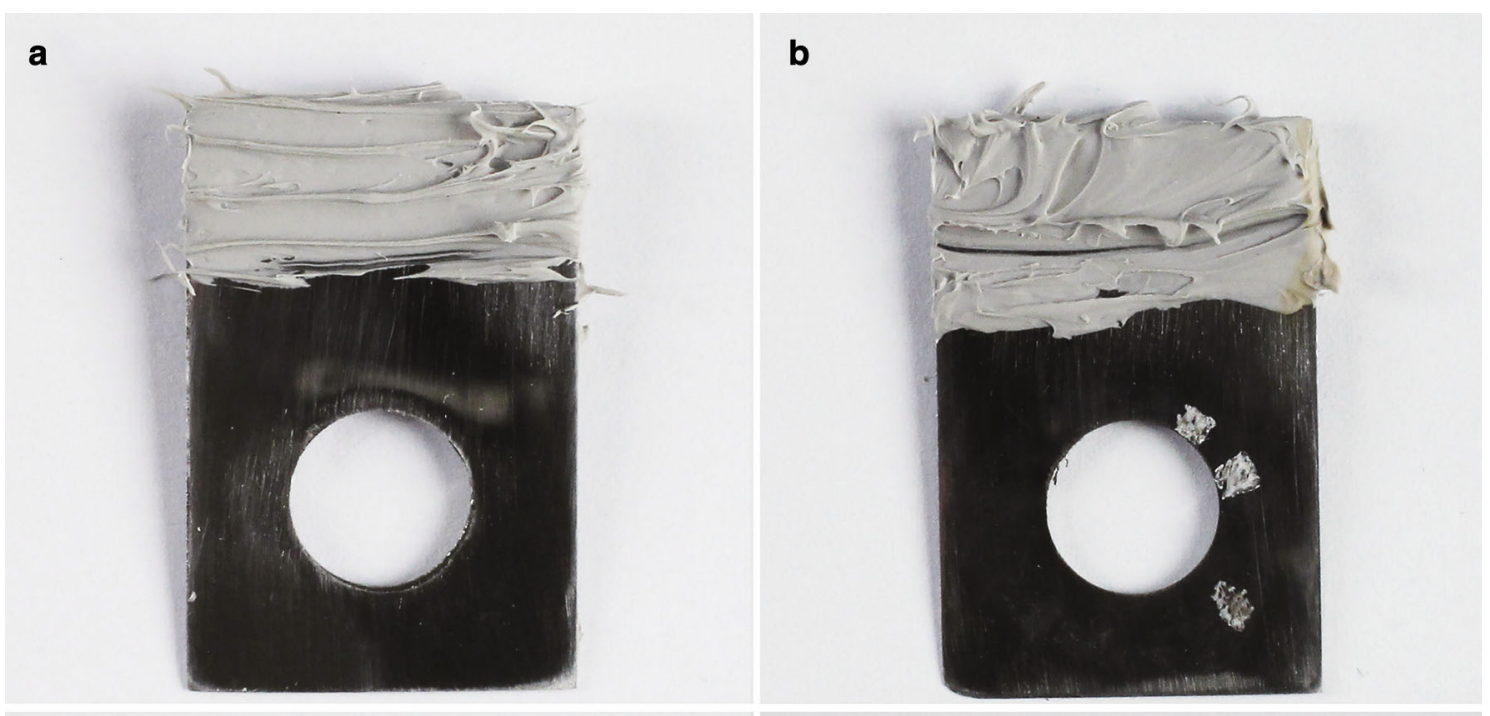

C

d

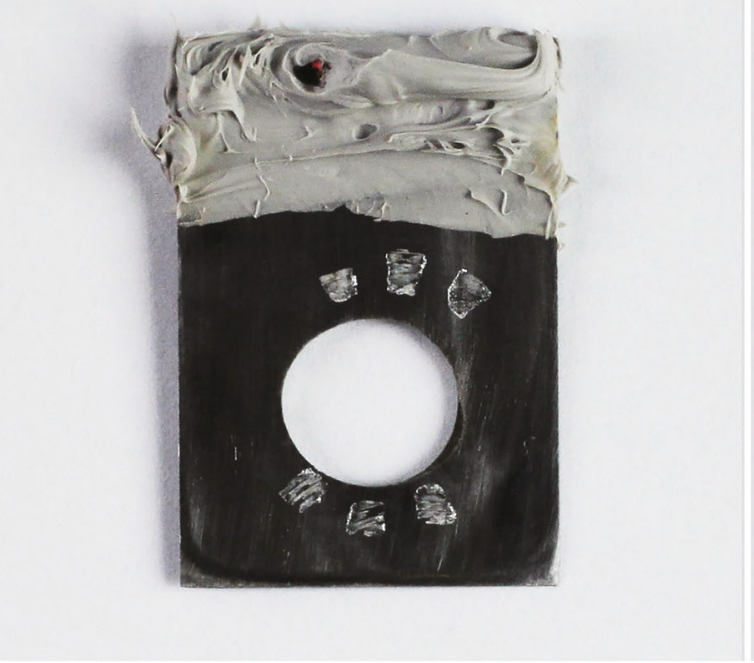

Fig. 6 Optical images of 436 specimens after the galvanostatic tests in $1 \mathrm{M}$ sodium chloride and $0.2 \mathrm{M}$ sodium sulfate solutions for a $2500 \mathrm{~s}$, b $4000 \mathrm{~s}$ and c $5500 \mathrm{~s}$, d after the potentiodynamic polarization test in $1 \mathrm{M}$ sodium chloride solution

Figure 8a shows great distinctive features between different concentrations of sulfate ions. Passive currents obviously decreased when sulfate ions were introduced. The breakdown potential largely increased as the sulfate ions concentration increased.

The similar trend is also observed in Fig. 8b, the breakdown potentials increased, and the passive currents decreased as the concentration of sulfate ions increased. However, differences were not as apparent as they showed in Fig. 8a. Breakdown potentials and passive currents changed following the same law, while they were very close though.

Figure 9 shows the SEM image of the specimen after potentiodynamic polarization tests. It was revealed that typical morphologies of the crevice corrosion could be observed with less other kind of obvious corrosion morphologies, which supported the suppression effect of sulfate ions. Some studies showed similarities with these results [30, 31]. It was convinced that there existed a competitive adsorption between sulfate ions and chloride ions, because of which the aggressiveness resulted from chloride ions were greatly weakened [16, 31, 32].

The IR drop mechanism can also be applied to explain these results that the breakdown potentials and the passive currents changed greatly in $0.1 \mathrm{M}$ sodium chloride-based solutions while did not change much in $1 \mathrm{M}$ sodium chloride-based solutions. With the addition of sulfate ions into the solution, not only the aggressiveness of the solution changed but the resistance of the solution changed as well. It was the same in the crevice area. When 0.1 and $0.2 \mathrm{M}$ sodium sulfate ions were introduced into the $0.1 \mathrm{M}$ sodium chloride solution, the resistance which was 


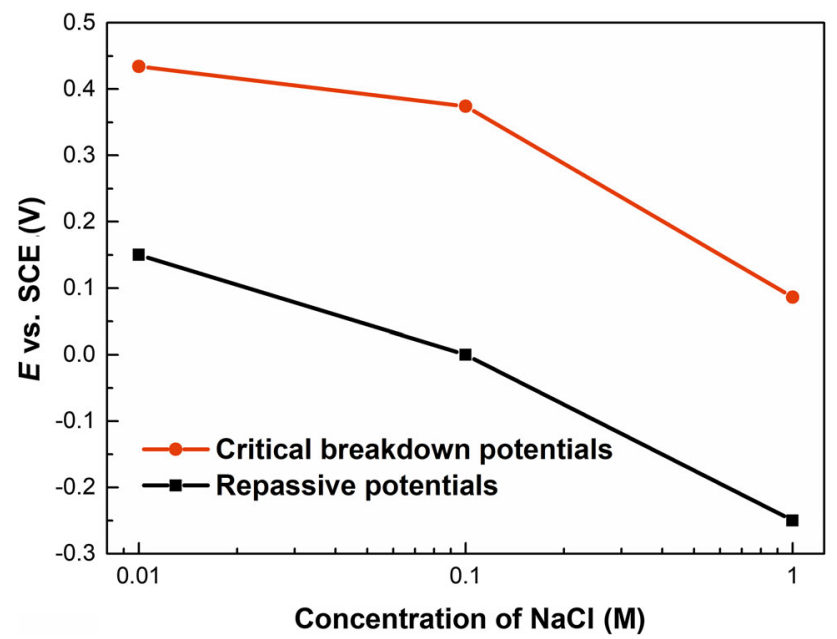

Fig. 7 Critical breakdown potentials and repassive potentials of creviced 436 stainless steel specimens in $0.01,0.1$ and $1 \mathrm{M}$ sodium chloride solutions

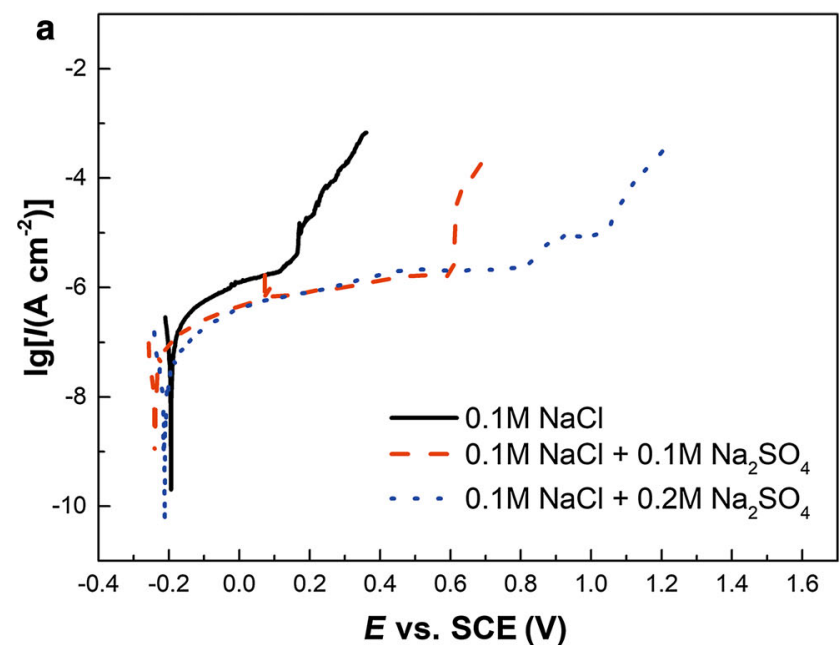

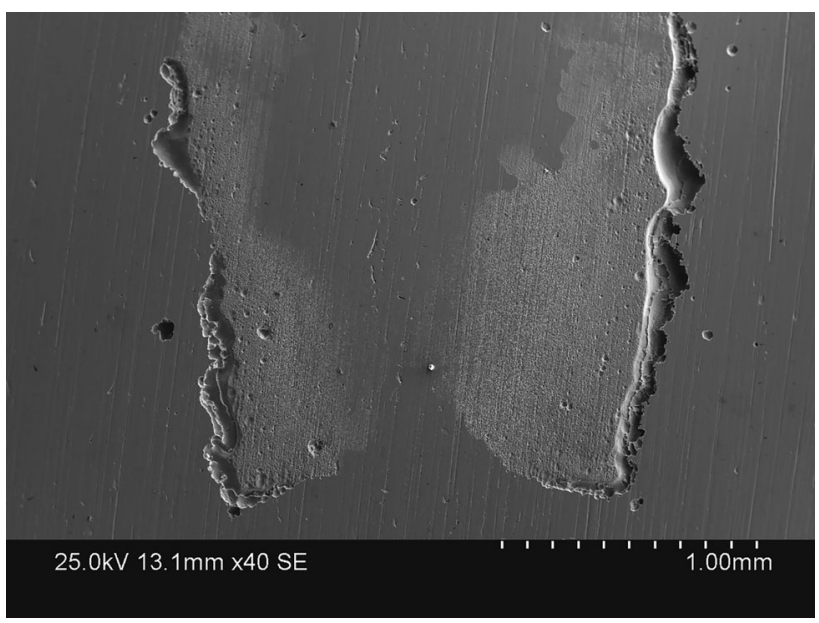

Fig. 9 SEM image of 436 stainless steels after potentiodynamic polarization test in $1 \mathrm{M}$ sodium chloride with $0.1 \mathrm{M}$ sodium sulfate solution

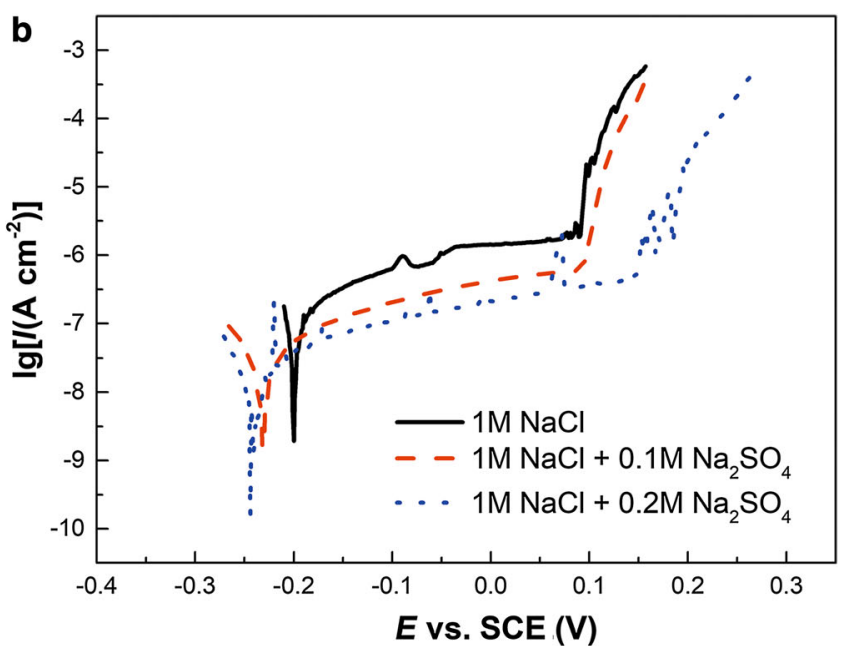

Fig. 8 Potentiodynamic polarization curves of 436 stainless steels in different solutions: a $0.1 \mathrm{M}$ sodium chloride with different sulfate ions, b $1 \mathrm{M}$ sodium chloride with different sulfate ions

mentioned in IR drop mechanism decreased dramatically, while little influence was made in $1 \mathrm{M}$ sodium chloride solution when the same concentration of sulfate ions was introduced into it.

\section{Conclusions}

(1) Crevice corrosion of 436 ferritic steels occurred in the solutions containing $0.01,0.1$ and $1 \mathrm{M}$ chloride ions at $30{ }^{\circ} \mathrm{C}$ when using potentiodynamic polarization tests. Solutions only containing chloride ions were thought to be too aggressive for studying crevice corrosion behaviors of 436 stainless steels. Sulfate ions were proved of inhibition effects in chloride ions containing solutions due to the competitive adsorption, and the changes of the solution resistance occurred when sulfate ions were added which can be explained by IR drop theory.

(2) Considering the degree of attacks, galvanostatic technique was more powerful than potentiodynamic polarization tests technique to form an obvious, deep, wide and continuous site of crevice corrosion, because the induction time is necessary for crevice corrosion to grow up. Repassivation potential measurements technique was proved to be a fast technique in evaluating crevice corrosion behaviors of 436 stainless steels. 
Acknowledgements The authors gratefully acknowledge Baosteel for providing specimens. This work is financially supported by the National Natural Science Foundation of China (Nos. 51501041 and 51671059).

\section{References}

[1] J.W. Oldfield, W.H. Sutton, Brit. Corros. J. 13, 13 (1978)

[2] J.W. Oldfield, W.H. Sutton, Brit. Corros. J. 13, 104 (1978)

[3] H.W. Pickering, R.P. Frankenthal, J. Electrochem. Soc. 119, 1297 (1972)

[4] F. Bocher, R. Huang, J.R. Scully, Corrosion 66, 055002 (2010)

[5] J.R. Hayes, J.J. Gray, A.W. Szmodis, C.A. Orme, Corrosion 62, 491 (2006)

[6] B.A. Kehler, J.R. Scully, Corrosion 61, 665 (2005)

[7] B.A. Kehler, G.O. Ilevbare, J.R. Scully, Corrosion 57, 1042 (2001)

[8] F. Bocher, F. Presuel-Moreno, J.R. Scully, J. Electrochem. Soc. C 155, 256 (2008)

[9] X. He, B. Brettmann, H. Jung, Corrosion 65, 449 (2009)

[10] K.J. Evans, A. Yilmaz, S.D. Day, L.L. Wong, J.C. Estill, R.B. Rebak, JOM 57, 56 (2005)

[11] A.K. Mishra, G.S. Frankel, Corrosion 64, 836 (2008)

[12] G.O. Ilevbare, K.J. King, S.R. Gordon, H.A. Elayat, G.E. Gdowski, T. Gdowski, J. Electrochem. Soc. B 152, 547 (2005)

[13] D.D. Macdonald, A.C. Scott, P. Wentrcek, J. Electrochem. Soc. 126, 1618 (1979)

[14] A. Anderko, N. Sridhar, D.S. Dunn, Corros. Sci. 46, 1583 (2004)

[15] M. Rincón Ortiz, R.M. Carranza, M.A. Rodríguez, J. Phys: Conf. Ser. 786, 012034 (2017)
[16] Y. Zuo, H. Du, J.P. Xiong, J. Mater. Sci. Technol. 16, 286 (2000)

[17] Y. Zuo, H.T. Wang, J.M. Zhao, J.P. Xiong, Corros. Sci. 44, 13 (2002)

[18] Y.L. Chou, Y.C. Wang, J.W. Yeh, H.C. Shih, Corros. Sci. 52, 3481 (2010)

[19] Y.Y. Chen, L.B. Chou, H.C. Shih, Mater. Chem. Phys. 97, 37 (2006)

[20] L. Niu, K. Nakada, Corros. Sci. 96, 171 (2015)

[21] L. Niu, H. Kato, K. Shiokawa, K. Nakamura, M. Yamashita, Y. Sakai, Mater. Trans. 54, 2225 (2013)

[22] ASTM G48-03, Annual Book of ASTM Standards, vol. 03.05 (ASTM International, West Conshohocken, PA, 2005)

[23] Z. Szklarska-Smialowska, J. Mankowski, Corros. Sci. 11, 953 (1978)

[24] M.A.M. Ibrahim, S.S. Abd El Rehim, M.M. Hamza, Mater. Chem. Phys. 115, 80 (2009)

[25] Q. Yang, J.L. Luo, Electrochim. Acta 46, 851 (2001)

[26] M.A. Ameer, A.M. Fekry, F.E. Heakal, Electrochim. Acta 50, 43 (2004)

[27] S.S. El-Egamy, W.A. Badaway, J. Appl. Electrochem. 34, 1153 (2004)

[28] E. Meguid, N.A. Mahmoud, S. Rehim, Mater. Chem. Phys. 63, $67(2000)$

[29] Q. Hu, G. Zhang, Y. Qiu, X. Guo, Corros. Sci. 53, 4065 (2011)

[30] T. Aoyama, Y. Sugawara, I. Muto, N. Hara, Corros. Sci. 127, 131 (2017)

[31] C.S. Brossia, R.G. Kelly, Corrosion 54, 145 (1998)

[32] T. Aoyama, Y. Sugawara, I. Muto, N. Hara, Corros. Sci. 127, 131 (2017) 